BNL-112748-2016-JA

\title{
Oxygen Reduction Kinetics on Pt Monolayer Shell Highly Affected by the Structure of Bimetallic AuNi Cores
}

\author{
Guangyu Chen, Kurian A. Kuttiyiel, Dong Su, Meng Li, \\ Chiu-Hui Wang, David Buceta, Chunyu Du, Yunzhi Gao, \\ Geping Yin, Kotaro Sasaki, Miomir B. Vukmirovic, Radoslav R. Adzic
}

Submitted to Chemistry of Materials

October 2016

Chemistry Department

Brookhaven National Laboratory

\author{
U.S. Department of Energy \\ USDOE Office of Science (SC), \\ Basic Energy Sciences (BES) (SC-22)
}

Notice: This manuscript has been authored by employees of Brookhaven Science Associates, LLC under Contract No. DE- SC0012704 with the U.S. Department of Energy. The publisher by accepting the manuscript for publication acknowledges that the United States Government retains a non-exclusive, paid-up, irrevocable, world-wide license to publish or reproduce the published form of this manuscript, or allow others to do so, for United States Government purposes. 


\section{DISCLAIMER}

This report was prepared as an account of work sponsored by an agency of the United States Government. Neither the United States Government nor any agency thereof, nor any of their employees, nor any of their contractors, subcontractors, or their employees, makes any warranty, express or implied, or assumes any legal liability or responsibility for the accuracy, completeness, or any third party's use or the results of such use of any information, apparatus, product, or process disclosed, or represents that its use would not infringe privately owned rights. Reference herein to any specific commercial product, process, or service by trade name, trademark, manufacturer, or otherwise, does not necessarily constitute or imply its endorsement, recommendation, or favoring by the United States Government or any agency thereof or its contractors or subcontractors. The views and opinions of authors expressed herein do not necessarily state or reflect those of the United States Government or any agency thereof. 


\title{
Oxygen Reduction Kinetics on Pt Monolayer Shell Highly Affected by the Structure of Bimetallic AuNi Cores
}

\author{
Guangyu Chen ${ }^{\dagger, \ddagger}$, Kurian A. Kuttiyiel ${ }^{\ddagger}$, Dong $\mathrm{Su}^{\S}$, Meng $\mathrm{Li}^{\ddagger}$, Chiu-Hui Wang ${ }^{\ddagger}$, \\ David Buceta ${ }^{\ddagger}$, Chunyu $\mathrm{Du}^{\dagger}$, Yunzhi Gao ${ }^{\dagger}$, Geping $\mathrm{Yin}^{\dagger} *$, Kotaro Sasaki ${ }^{\ddagger} *$, \\ Miomir B. Vukmirovic ${ }^{\ddagger}$, Radoslav R. Adzic ${ }^{\ddagger *}$
}

${ }^{\dagger}$ State Key Laboratory of Urban Water Resource and Environment, School of Chemical Engineering and Technology, Harbin Institute of Technology, Harbin 150001, China

${ }^{\ddagger}$ Chemistry Department and ${ }^{\S}$ Center for Functional Nanomaterials, Brookhaven National Laboratory, Upton, NY 11973, USA

*To whom correspondence should be addressed:

Emails: yingphit@hit.edu.cn; ksasaki@bnl.gov; adzic@bnl.gov 


\section{ABSTRACT}

We describe pronounced effects of structural changes of the AuNi cores on the oxygen reduction reaction (ORR) activity of a Pt monolayer shell. The study of alloyed AuNi nanoparticles compared with AuNi core-shell structured nanoparticles revealed configurations having different electronic and electrochemical properties. Controlled alloying of Au with Ni was essential to tune the electronic properties of Au interacting with the Pt monolayer shell to achieve suitable adsorption of $\mathrm{O}_{2}$ on Pt for expediting the ORR. The alloyed AuNi nanoparticles made the Pt shell more catalytically active for the ORR than the core-shell structured AuNi nanoparticles. The Pt monolayer supported on the alloyed AuNi nanoparticles showed the Pt mass and specific activities as high as $1.52 \mathrm{~A} \mathrm{mg}^{-1}$ and $1.18 \mathrm{~mA} \mathrm{~cm}^{-2}$ respectively, with almost no loss over 5,000 cycles of stability test. This high ORR activity is ascribed to the role of non-specific steric configuration of $\mathrm{Ni}$ atoms changing the electronic properties of the alloy that affect the oxygen and water interaction with the Pt shell and facilitate increased ORR kinetics. 


\section{INTRODUCTION}

The oxygen reduction reaction (ORR) has long been the subject of considerable research in developing fuel cells and metal-air batteries because such energy devices combine oxygen with fuel molecules or active metals to generate electricity without carbon footprint on environment. ${ }^{1-5}$ Though molecular oxygen is thermodynamically unstable, ${ }^{6,7}$ its unusual electron configuration bearing triplet electronic ground state, poses a significant energy barrier for its direct reaction with most species that are usually in the singlet state. ${ }^{8-10}$ This mismatch-induced energy barrier challenges scientists to design ORR catalysts with peculiar electronic and chemical properties that can enable proper surface interaction. Examples include Pt- or Pd- based nanostructures, ${ }^{1,2,11}$ non-precious transition-metal macrocycles, ${ }^{6,12,13}$ and metal-free doped carbon materials. ${ }^{9,14,15}$ Pt-based nanostructures are the most active and stable ORR electrocatalysts known to date. ${ }^{1,16}$ However, this unique feature is far too compromised by the scarcity and cost of Pt to be practically appreciated in devising energy frameworks, as the U.S. Department of Energy requires that the Pt mass activity target should be nearly four times higher than that of the standard Pt/C. ${ }^{17}$

To accord with the target, a second, inexpensive transition metal was adopted to formulate Pt-alloyed and/or shelled nanocrystals to tune the $d$-band center of the top Pt layer in order to promote the dissociative adsorption of $\mathrm{O}_{2}$, and/or, to eliminate a significant amount of $\mathrm{Pt}$ while achieving comparable or even higher cost-effectiveness. ${ }^{18-21}$ Platinum Monolayer $\left(\mathrm{Pt}_{\mathrm{ML}}\right)$ electrocatalysts where a thin row of Pt atoms is placed on less-noble substrates play an important role in achieving these properties. ${ }^{22-24}$ Such $\mathrm{Pt}_{\mathrm{ML}}$ electrocatalysts often exhibited an order-of-magnitude higher mass activity than commercial Pt nanoparticles. However, most of 
the tangible $\mathrm{Pt}_{\mathrm{ML}}$ electrocatalysts experience loss of their inner core during exceeded potential cycles and therefore using a good corrosion resistant core should circumvent that. ${ }^{4,25} \mathrm{Au}$ owing to its high redox potential can be a good candidate for the $\mathrm{Pt}_{\mathrm{ML}}$ electrocatalysts but its tendency to segregate to the surface under ORR conditions destabilizes the catalyst. ${ }^{26}$ Alloying Au to a cheaper metal can improve its effectiveness for both activity and stability in terms of their components, composition, and steric configuration. ${ }^{27,28}$ The $\mathrm{Pt}_{\mathrm{ML}}$ electrocatalysts on the M@Au (M denotes cheaper metal, such as $\mathrm{Ni}$ and $\mathrm{Fe}$ ) core-shell structured substrates have been studied previously, ${ }^{27-29}$ but $\mathrm{Pt}_{\mathrm{ML}}$ on $\mathrm{Au}-\mathrm{M}$ alloy structured substrates have never been investigated because the Au-M alloyed nanoparticle is relatively difficult to synthesize. However, proper electrocatalyst design requires a fundamental understanding of the structure-function relationship, specifically how Au placement can affect the catalytic properties of $\mathrm{Pt}_{\mathrm{ML}}$ electrocatalyst. In this study we report on the AuNi bimetallic core that was engineered to create two generic types of steric configuration: core-shell and alloy structures successfully synthesized by a fast co-reduction method and subsequent thermal annealing. The two representative structures were chosen because the phase behavior of a binary system varies with the hetero- and homo-atomic interactions, while we kept their components and composition identical to highlight the influence of the electronic and steric structure of the core. Our findings demonstrate that the ORR activity and stability of the $\mathrm{Pt}_{\mathrm{ML}}$ was improved greatly by the AuNi alloyed core that modified the lattice strain and its $d$-band center. We also discussed the importance on the choice of two elements $\mathrm{Au}$ and $\mathrm{Ni}$ with emphasis on the electrochemical inertness of Au and its role in stabilizing both the core and the Pt shell. 


\section{EXPERIMENTAL}

\section{Material Synthesis}

Carbon-supported AuNi alloy and Ni-Au core-shell nanoparticles, denoted as AuNi-a/C and $\mathrm{AuNi}-\mathrm{cs} / \mathrm{C}$, respectively, were synthesized by combination of a chemical co-reduction approach and subsequent thermal annealing. ${ }^{30,31}$ To start with, $61.4 \mathrm{mg}$ of $\mathrm{HAuCl}_{4} \cdot 3 \mathrm{H}_{2} \mathrm{O}$ (0.156 mmol) and $40.1 \mathrm{mg}$ of $\mathrm{Ni}$ (acac) $2(0.156 \mathrm{mmol})$ were dissolved in a mixture solvent comprising of $10 \mathrm{ml}$ dioctyl ether and $2.5 \mathrm{ml}$ oleylamine (OAm, 70\%) at $45-50{ }^{\circ} \mathrm{C}$, generating Solution I. On the other hand, a $1.5 \mathrm{ml}$ of butyl-lithium (butyl-Li, 2M in cyclohexane) solution and a $15 \mathrm{ml}$ of dioctyl ether, separately, were stepwise syringed into a three-neck round bottom flask under protection of dry Ar, generating Solution II. Afterward, Solution I was immediately injected into Solution II under stirring causing the formation of a dark brown colloid solution, to which, 30 min later, we added a $10 \mathrm{ml}$ dioctyl ether suspension of $160 \mathrm{mg}$ carbon black (Vulcan ${ }^{\circledR}$ XC-72R). Upon continuous stirring the as-prepared suspension was heated at $120{ }^{\circ} \mathrm{C}$ for an hour followed by increase in temperature to $230{ }^{\circ} \mathrm{C}$ for another hour producing carbon supported AuNi (AuNi/C) nanoparticles. The centrifuged AuNi/C particles was subjected to surface engineering by incubating it in n-butylamine and then ethanol to remove the surfactant, OAm, adsorbed on the particles' surface prior to serving as precursors for AuNi-a/C and AuNi-cs/C nanoparticles. ${ }^{32}$

To produce AuNi-a/C, the as-prepared AuNi/C sample was annealed at $200{ }^{\circ} \mathrm{C}$ under a reducing atmosphere $\left(15 \% \mathrm{H}_{2}\right.$ by volume in $\left.\mathrm{Ar}\right)$ for 2 hours in a tube furnace. The AuNi-cs/C was produced by annealing the AuNi/C sample at $400{ }^{\circ} \mathrm{C}$ for 1 hour. For comparison, 
carbon-supported $\mathrm{Au}(\mathrm{Au} / \mathrm{C})$ was prepared using the same procedure (particle size $5 \mathrm{~nm})$. For all the three materials, we ensured the same loading of $20 \mathrm{wt} \%$ of metals by pre-determined amounts of precursors in the synthesis. Finally, a $\mathrm{Pt}_{\mathrm{ML}}$ was placed on the AuNi-a/C and AuNi-cs/C nanostructures to form new electrocatalysts, viz. $\mathrm{Pt}_{\mathrm{ML}} \mathrm{AuNi}-\mathrm{a} / \mathrm{C}$ and $\mathrm{Pt}_{\mathrm{ML}} \mathrm{AuNi}-\mathrm{cs} / \mathrm{C}$, by the galvanic displacement of a copper monolayer underpotentially deposited (UPD) on these two bimetallic supports. ${ }^{33}$

\section{Materials Characterization}

The as-prepared nanostructures were characterized via X-ray diffraction (XRD) at National Synchrotron Light Source (NSLS), Brookhaven National Laboratory (BNL) using X18A beamline. The wavelength of X-ray used was $1.0 \AA$. Transmission electronic microscopy (TEM) images were taken with a JEOL 3000F TEM operating at $300 \mathrm{kV}$. The Scanning transmission electron microscopy (STEM) and Electron Energy Loss Spectroscopy (EELS) measurements were performed with the dedicated aberration-corrected STEM (Hitachi HD-2700C) coupled with a modified Gatan Enfina ER spectrometer. Energy dispersive X-ray spectroscopic (EDX) characterization was performed using a Hitachi S-3400 scanning electron microscope (SEM) with a built in EDX. X-ray absorption spectroscopic (XAS) measurements were conducted using the Beamline X19A of NSLS at BNL. The measurements were carried out at the Au L3-edge (11919 eV), and Ni K-edge (8333 eV) at room temperature. The $\mathrm{Au} \mathrm{L}_{3}$-dege was measured in transmission mode, while the Ni K-edge was measured in fluorescence mode since the signal of Ni K-edge in transmission mode was too weak and less sensitive. All the XAS data were processed with Athena and Artemis software. $^{34}$ The Fourier-transform (FT) extended X-ray absorption fine structure (EXAFS) 
spectra of AuNi-cs/C and AuNi-a/C are fitted with first-shell fits to determine structural parameters, such as coordination number $(N)$ and bond distance $(R) .{ }^{35,36}$ The following constraints were applied for both samples: (i) the ratio of coordination numbers $\left(N_{\mathrm{Au}-\mathrm{Ni}} / N_{\mathrm{Ni}-\mathrm{Au}}\right)$ is equal to the atomic ratio, $x_{\mathrm{Au}} / x_{\mathrm{Ni}}$; (ii) the $\mathrm{Au}-\mathrm{Ni}$ bond distance in respective samples is same as that measured from either edge, that is, $R_{\mathrm{Au}-\mathrm{Ni}}=R_{\mathrm{Ni}-\mathrm{Au}}$; and (iii) the bond length disorder parameters of heterogeneous metal bonds are the same as those measured from opposite atoms (i.e., $\sigma_{\text {Au-Ni }}^{2}=\sigma_{\text {Ni-Au }}^{2}$ ). As previously described in the literature we calculated the following parameters to predict the structure models of the AuNi nanoparticles by using equations (1) and (2). ${ }^{37}$

$$
\begin{gathered}
J_{\text {Au }}=\frac{P_{\text {observed }}}{P_{\text {random }}} \times 100 \% \\
J_{\mathrm{Ni}}=\frac{R_{\text {observed }}}{R_{\text {random }}} \times 100 \%
\end{gathered}
$$

where $J_{\mathrm{Au}}=$ extent of alloying of element $\mathrm{Au}$ and $J_{\mathrm{Ni}}=$ extent of alloying of element $\mathrm{Ni}$; the parameter $P_{\text {observed }}$ can be defined as a ratio of the scattering atoms Ni coordination number around $\mathrm{Au}$ atoms $\left(N_{\mathrm{Au}-\mathrm{Ni}}\right)$ to the total coordination number of absorbing atoms $\left(\sum N_{\mathrm{Au}-\mathrm{i}}\right)$, viz. $P_{\text {observed }}=N_{\mathrm{Au}-\mathrm{Ni}} / \sum N_{\mathrm{Au}-\mathrm{i}}$; Similarly the parameter $R_{\text {observed }}$ can be defined as a ratio of the scattering atoms $\mathrm{Au}$ coordination number around $\mathrm{Ni}$ atoms $\left(N_{\mathrm{Ni}-\mathrm{Au}}\right)$ to the total coordination number of absorbing atoms $\left(\sum N_{\mathrm{Ni}-\mathrm{i}}\right)$, viz. $R_{\text {observed }}=N_{\mathrm{Ni} \text {-Au }} / \sum N_{\mathrm{Ni- \textrm {i }}} ; P_{\text {random }}$ and $R_{\text {random }}$ are taken as 0.5 as the atomic ratio of $\mathrm{Au}$ and $\mathrm{Ni}$ is $1: 1$.

\section{Electrochemical Measurements}

We confined the electrocatalysts on 5-mm diameter glassy carbon electrodes (GCE, Pine Instrument, USA) for electrochemical measurements. The electrocatalysts were dispersed in 
water by sonication to give a content of $1.0 \mathrm{mg} / \mathrm{mL}$, and a $10 \mu \mathrm{L}$ of the dispersion was placed on a GCE. For comparison, we prepared E-TEK Pt/C (20 wt\%, 4 nm diameter) electrode by the same procedure. All the measurements were carried out with a typical three-electrode system consisting of a catalyst-loaded GCE working electrode and a platinum-flag counter electrode. While an Ag/AgCl reference electrode was used throughout the electrochemical measurements, all the potentials presented are quoted versus a reversible hydrogen electrode (RHE). $0.1 \mathrm{M} \mathrm{HClO}_{4}$ electrolyte solution was prepared by mixing $18.2 \mathrm{M} \Omega \mathrm{cm}$ Milli-Q UV deionized water with perchloric acid (optima grade, Fisher Scientific). Unless specified otherwise, rotating disc electrode (RDE) voltammograms were recorded at the rotating speed of $1600 \mathrm{rpm}$ with a potential scan rate of $10 \mathrm{mV} \mathrm{s}^{-1}$. The amount of Pt at the electrode was related to the coulombic charge associated with the underpotential deposition of a copper monolayer. We calculated the electrochemical surface-areas (ECSAs) by integrating the hydrogen adsorption peak over time in the cyclic voltammograms, using the value of $210 \mu \mathrm{C}$ $\mathrm{Cm}^{-2}$ ECSA. $^{17}$

\section{RESULTS AND DISCUSSION}

Alloying $\mathrm{Au}$ and Ni nanoparticles poses a grand challenge because these two metals are thermodynamically immiscible at bulk within a large range of temperature (Figure S1), and their reduction potentials greatly differ from one another. ${ }^{38}$ Conventional reducing agents (e.g., $\mathrm{NaBH}_{4}$ ) usually preferentially reduce $\mathrm{Au}$ in $\mathrm{Ni}-\mathrm{Au}$ co-existing systems. ${ }^{39}$ However, butyl-Li has an extremely low standard potential $\left(1.0 \mathrm{~V}\right.$ vs. $\left.\mathrm{Li} / \mathrm{Li}^{+}\right)$so as to be able to reduce $\mathrm{Ni}$ and $\mathrm{Au}$ almost simultaneously and thus produce the AuNi alloy. In order to obtain clean 
AuNi surface to remove the adsorbed n-butylamine and the similar particle size as that of the AuNi-cs/C, the as-prepared AuNi/C was annealed at $200^{\circ} \mathrm{C}$ for 2 hours. Annealing at $400{ }^{\circ} \mathrm{C}$ induce the segregation of $\mathrm{Au}$ on $\mathrm{Ni}$ due to the difference in surface energy, ${ }^{40}$ thereby causing the formation of core-shell structure. Figure 1 schematically displays the synthesis of Au-Ni binary metal nanoparticles with alloy and core shell structure, respectively, and the deposition of $\mathrm{Pt}_{\mathrm{ML}}$ on them.

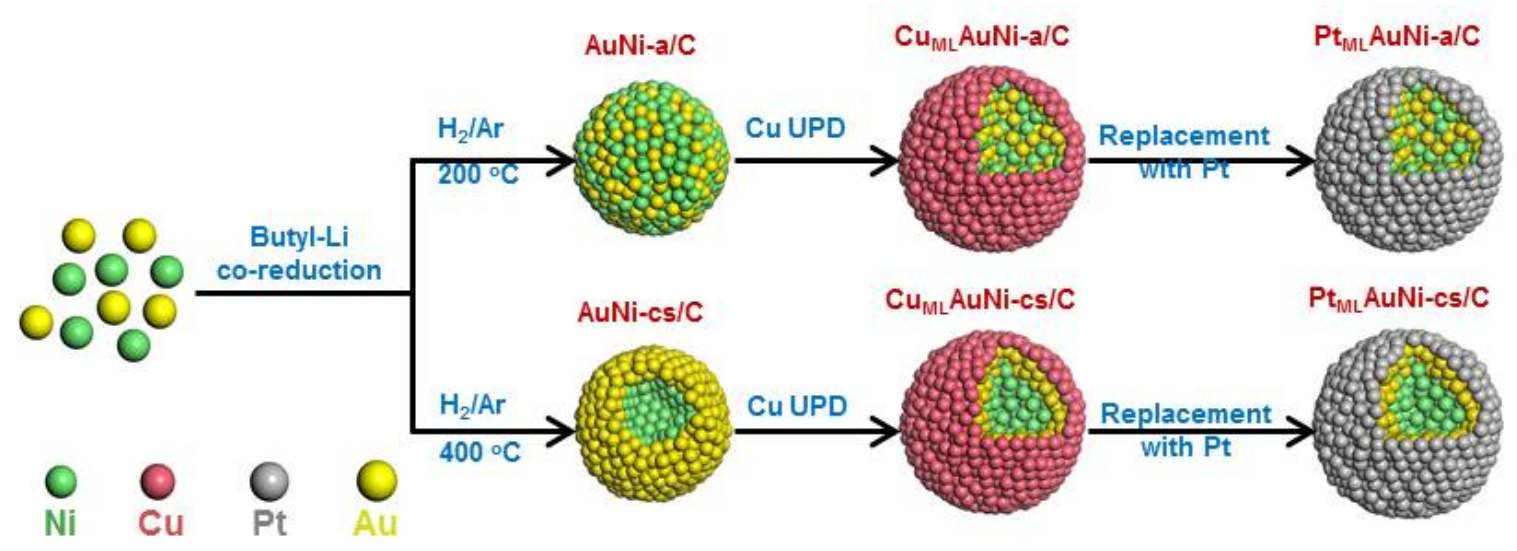

Figure 1. Schematic illustration of the stepwise synthesis of $\mathrm{Pt}_{\mathrm{ML}} \mathrm{AuNi}-\mathrm{a} / \mathrm{C}$ and $\mathrm{Pt}_{\mathrm{ML}} \mathrm{AuNi}$-cs/C electrocatalysts.

The morphology and particle size of the as-produced AuNi-cs/C and AuNi-a/C were examined by TEM. Figure S2a\&b show the typical low-magnification images for AuNi-cs/C and AuNi-a/C, respectively. Both the nanoparticles have smooth and round surfaces with a diameter of 4-7 nm (see the particle-size distributions in the insets of Figure S2), which are similar to the as-prepared AuNi/C (Figure S2c); the average diameters were determined to be $5.3 \mathrm{~nm}$ and $5.8 \mathrm{~nm}$ for AuNi-cs/C and AuNi-a/C, respectively. The metallic compositions of Au and $\mathrm{Ni}(\mathrm{Au}: \mathrm{Ni}=1: 1)$ verified by the EDX analysis (Figure S3).

To gain insight in the topological structures of AuNi-a/C and $\mathrm{AuNi}-\mathrm{cs} / \mathrm{C}$, we examined the 
nanoparticles by EELS in association with high-angle annular dark-field scanning transmission electron microscopy (HAADF)-STEM. Figure 2a\&b show representative AuNi-cs/C and AuNi-a/C single nanoparticles and the corresponding signal intensity profiles of Au and Ni components, respectively, in a line scan across the whole nanoparticle (arrow). The EELS line-scan profiles of $\mathrm{Ni}$ and $\mathrm{Au}$ from AuNi-cs reveal the core-shell structure of the nanoparticle with the $\mathrm{Ni}$ in the core and Au shell; the Ni-rich core has a diameter of $4.2 \mathrm{~nm}$ surrounded by Au with a shell thickness of 0.8-0.9 nm, as highlighted by the dotted lines in Figure 2a. However, similar line-scan profiles of $\mathrm{Au}$ and Ni from AuNi-a indicates that it is a homogeneous, alloy structured nanoparticle (Figure 2b). In addition, we scanned the two-dimensional (2D) mappings of $\mathrm{Au}$ and $\mathrm{Ni}$ for other single nanoparticles to further confirm their structures. The overlapped image of $\mathrm{Au}$ (red) and Ni (green) composite mappings exhibits a region-specific segregation of Au along the particulate's perimeter, as shown in Figure 2c, indicating an Au-skinned core-shell nanostructure. Furthermore, the shell and the core in AuNi-cs, respectively, were measured ca. $7.0 \mathrm{~nm}$ and $0.8 \mathrm{~nm}$ according to the intensity cutoffs in the HAADF and EELS intensities. By contrast, AuNi-a/C (Figure 2d) exhibits a non-specific distribution for both $\mathrm{Au}$ and $\mathrm{Ni}$ atoms, denoting an overall homogeneous alloyed structure. 

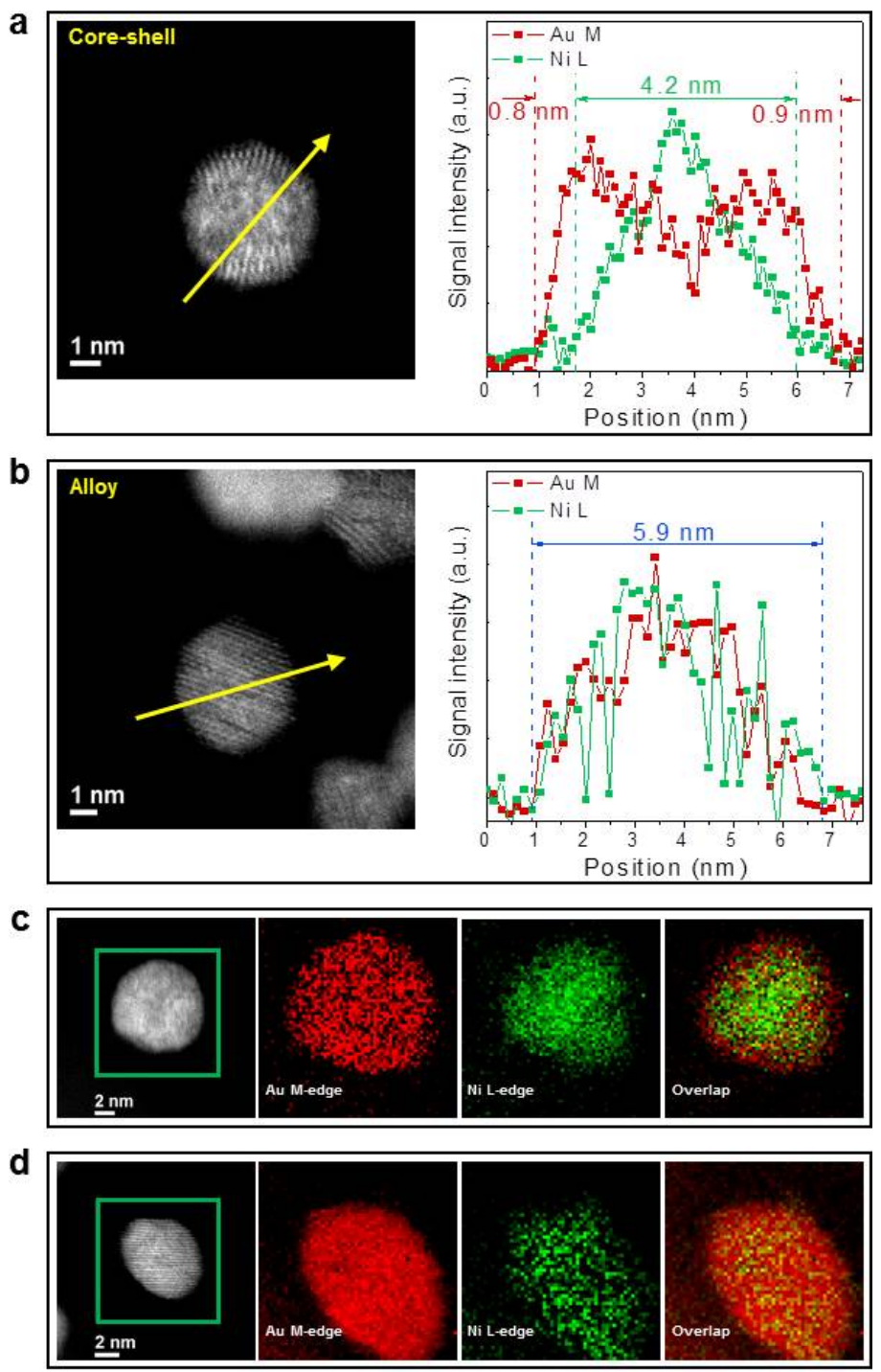

Figure 2. (a, b) HAADF-STEM images of single nanoparticles and their corresponding EELS line-scan profiles of $\mathrm{Au}$ (red) and $\mathrm{Ni}$ (green) and (c, d) HAADF-STEM images of single nanoparticles and their corresponding 2D EELS maps of Au (red) and Ni (green) and their overlapped images from AuNi-cs/C and AuNi-a/C samples, respectively.

Figure 3 shows the XRD patterns of as-prepared AuNi/C, AuNi-a/C and AuNi-cs/C together with two references, viz. the standard diffraction from Au (JCPDS 04-0784) and Ni (JCPDS 04-0850). By comparison, the peak-positions of AuNi/C and AuNi-a/C are totally the same, which indicates that the original structure is unchanged after annealing at $200{ }^{\circ} \mathrm{C}$ (only the XRD result of $\mathrm{AuNi}-\mathrm{a} / \mathrm{C}$ is discussed below). Further, the peaks from AuNi-cs/C and AuNi-a/C can be well indexed to the reflection of the lattice planes of (111), (200), (220), 
and (311) of the face-centered cubic Au crystals (fcc, space group Fm-3m). The (111) peak for pure $\mathrm{Au}$ is at $2 \theta$ angle of $24.56^{\circ}$, but the $\mathrm{AuNi}-\mathrm{cs} / \mathrm{C}$ and $\mathrm{AuNi}-\mathrm{a} / \mathrm{C}$ (111) peaks shift to higher angles of $c a .25 .13^{\circ}$ and $25.94^{\circ}$ respectively, indicating the lattice contraction of $\mathrm{Au}$ in both AuNi-cs/C and AuNi-a/C nanoparticles due to the involvement of $\mathrm{Ni}$ atoms. Furthermore, a small peak of $\mathrm{Ni}(200)$ at $2 \theta$ angle $32.81^{\circ}$ and a shoulder of Ni (111) at $2 \theta$ angle $28.33^{\circ}$ from AuNi-cs/C were observed. This confirms the existence of Ni-rich cores in AuNi-cs/C catalyst because their XRD pattern is the convolution of signals from the Ni-rich core and the Au shell, respectively. ${ }^{41}$ On the other hand, no Ni diffraction peak was observed from AuNi-a/C catalyst, demonstrating a well-alloyed structure. AuNi-a/C nanoparticles show a high degree of alloying, as evidenced by the higher $2 \theta$ angle and consequently a higher lattice contraction compared to their counterpart. On the basis of the Scherrer Equation, we calculated the Au-Ni particle sizes of AuNi-cs/C and AuNi-a/C samples (Table S1), which are similar with the above TEM visualizations.

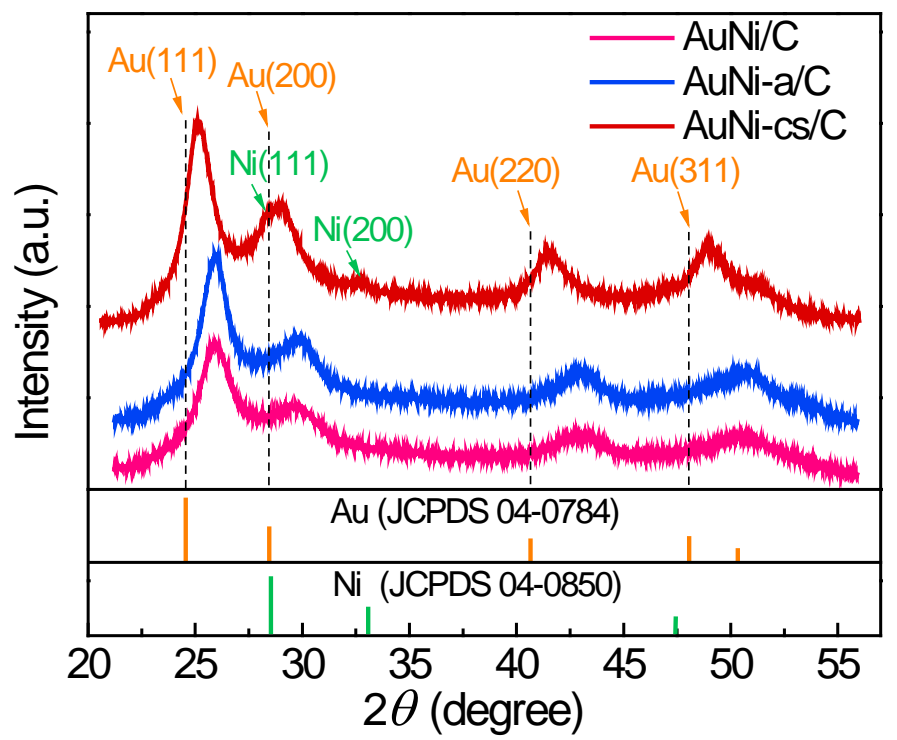

Figure 3. Synchrotron XRD patterns of as-prepared AuNi/C, AuNi-a/C and AuNi-cs/C. The bars are standard XRD patterns of Au (orange) and Ni (green). 
XAS measurements for both AuNi-a/C and AuNi-cs/C allowed us to further understand their structural and physiochemical properties. The XAS spectra of the $\mathrm{Au} \mathrm{L}_{3}$ and $\mathrm{Ni} \mathrm{K}$ edges are shown in Figure 4 to compare with those from their corresponding references. The X-ray

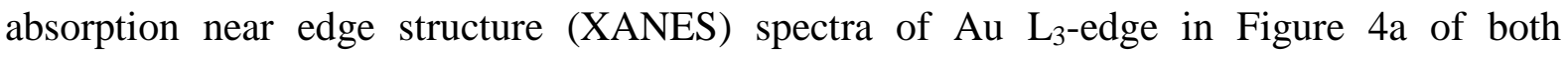
AuNi-a/C and AuNi-cs/C deviated from that of the Au foil - particularly in between the photon energy of $11925-11940 \mathrm{eV}$ - which we attributed to electronic coupling with its neighboring $\mathrm{Ni}$ atoms. Furthermore, the absorption intensity corresponding to this photon-energy range reflects transition of the $2 \mathrm{p}_{3 / 2}$ electrons to a vacant $5 d$-orbit and therefore, AuNi-a/C and AuNi-cs/C had a partial depletion of the Au d-band in relation to pure $\mathrm{Au}^{4,42,43}$ We note that the intensity from $\mathrm{AuNi}-\mathrm{a} / \mathrm{C}$ in this energy region is slightly higher than that from AuNi-cs/C, implying that the depletion of $d$-band in AuNi-a/C is greater than that in AuNi-cs/C. The same inference was true when analyzing the Ni K-edge XANES spectra. In contrast to the $\mathrm{Au} \mathrm{L}_{3}$-edge XANES, where the absorption intensity of AuNi-a/C or AuNi-cs/C was relatively high, the Ni K-edge XANES spectra displayed that the absorption of AuNi-a/C or AuNi-cs/C was subtly lowered near the photon energy of $8335 \mathrm{eV}$ (Ni K-pre-edge, highlighted by orange gridlines in Figure 4b). This depression was designated by the same way to a partial filling of the Ni $d$-band that greatly consisted with the observations in the above $\mathrm{Au} \mathrm{L} \mathrm{L}_{3}$-edge XANES. ${ }^{44}$ The modification of electronic states in $\mathrm{AuNi} / \mathrm{C}$ substrates will be one of the effects that cause the enhancement of ORR activity in Pt MLs on them, as discussed later. 

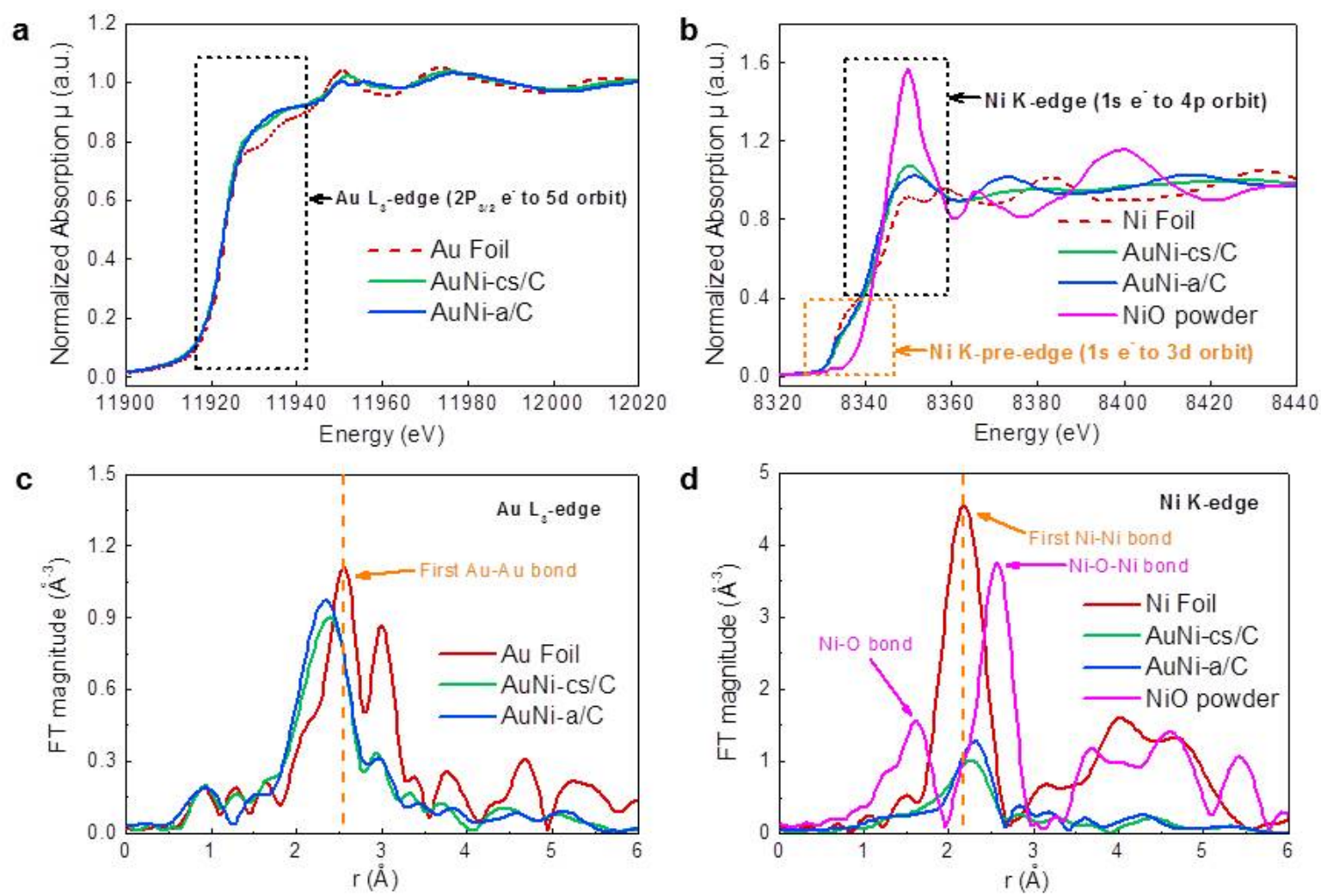

Figure 4. X-ray absorption studies. ( $a$ and b) XANES spectra and (c and d) FT-EXAFS spectra of $\mathrm{Au} \mathrm{L}_{3}$ and Ni K edges obtained from AuNi-cs/C, AuNi-a/C, and the references (Au foil, $\mathrm{Ni}$ foil, and $\mathrm{NiO}$ powder).

The FT-EXAFS spectra of $\mathrm{Au} \mathrm{L}_{3}$-edge, obtained from AuNi-a/C, AuNi-cs/C, and the reference Au foil, show the corresponding characteristic Au-Au bonding in $r$ space shown in Figure 4c. It was apparent that the addition of $\mathrm{Ni}$ atoms in the nanoparticles caused the peak to shift, reducing the Au-Au distance compared to Au foil. This peak-position shift is related to the contraction of Au lattice due to the geometrical interaction between the Au- and $\mathrm{Ni}$-atoms, while the decreasing in the peak intensity in comparison to that in bulk Au is due to the size truncation effect expected in the nanoparticles. ${ }^{45}$ The larger Au-Au bond distance for the core-shell nanoparticles compared to the alloyed counterpart indicates that interaction of $\mathrm{Ni}$ atoms is much higher for the alloyed nanoparticles. On the other hand, the $\mathrm{Ni}-\mathrm{Ni}$ peak shifts of AuNi-a/C and AuNi-cs/C to higher lengths with respect to the Ni foil peak at $2.2 \AA$ 
can also be attributed to the geometrical effect by Au (Figure 4d). Moreover, no Ni oxide formation was observed for both the nanoparticles. The Ni-Ni distance for the AuNi-cs/C nanoparticles is lower than that of AuNi-a/C, indicating that Au atom interaction to $\mathrm{Ni}$ atom is less for the core-shell structure. These results suggest a good alloying of $\mathrm{Au}$ and $\mathrm{Ni}$ in AuNi-a/C, and the segregation of Au in AuNi-cs/C. ${ }^{36,44,46}$

The fitting results for the $\mathrm{Au} \mathrm{L}_{3}$ and $\mathrm{Ni} \mathrm{K}$ edges of the AuNi-a/C and AuNi-cs/C samples are shown in Figure S4. There is good agreement between the fits and the original spectra. The results of coordination numbers, bond distances and passive electron reduction factors are summarized in Table 1\&S2, which are essential to predict the structure models of nanoparticles. For an ideal A-B binary solid-solution alloyed nanoparticle, the ratio (relative to the A atom) of the coordination number $N_{\mathrm{A}-\mathrm{A}}$ to $N_{\mathrm{A}-\mathrm{B}}$ is equal to the corresponding atomic ratio $x_{\mathrm{A}} / x_{\mathrm{B}}$ of the elements in the bulk (i.e., $N_{\mathrm{A}-\mathrm{A}} / N_{\mathrm{A}-\mathrm{B}}=x_{\mathrm{A}} / x_{\mathrm{B}}$ ). ${ }^{46,47}$ The statistical distribution of the two elements is characterized by equal sums of coordination numbers of one metal to that of the other, that is, $N_{\mathrm{A}-\mathrm{M}}=N_{\mathrm{B}-\mathrm{M}}$. The ratios of the coordination numbers for $\mathrm{AuNi}$-a/C sample, that is, $N_{\mathrm{Au}-\mathrm{Au}} / N_{\mathrm{Au}-\mathrm{Ni}}=1.15$ and $N_{\mathrm{Ni}-\mathrm{Ni}} / N_{\mathrm{Ni}-\mathrm{Au}}=1.21$, are in reasonably good agreement with EDX results $\left(x_{\mathrm{Au}} / x_{\mathrm{Ni}}=1\right)$ within the range of their experimental errors. Furthermore, the sum of coordination number for $\mathrm{Au}\left(N_{\mathrm{Au}-\mathrm{Au}}+N_{\mathrm{Au}-\mathrm{Ni}}=10.1\right)$ agrees well with that of $\mathrm{Ni}\left(N_{\mathrm{Ni}-\mathrm{Ni}}+N_{\mathrm{Ni}-\mathrm{Au}}=10.4\right)$, indicating a homogeneous distribution of $\mathrm{Au}$ and $\mathrm{Ni}$ atoms in the particles without any preferential accumulation of one metal around the other. Using the equations of (1) and (2), $J_{\mathrm{Au}}$ and $J_{\mathrm{Ni}}$ of $\mathrm{AuNi}-\mathrm{a} / \mathrm{C}$ are determined to be $93 \%$ and $91 \%$, respectively, representing that $\mathrm{Au}$ and $\mathrm{Ni}$ atoms are well dispersed randomly and the catalyst has a solid-solution structure since $J_{\mathrm{A}}$ and $J_{\mathrm{B}}$ values are $100 \%$ for an ideal A-B 
solid-solution. ${ }^{37}$

For AuNi-cs/C sample, the coordination numbers obtained are quite different from those from $\mathrm{AuNi}$-a/C. Both the ratios of the coordination numbers, $N_{\mathrm{Ni}-\mathrm{Ni}} / N_{\mathrm{Ni}-\mathrm{Au}}=2.13$ and $N_{\mathrm{Au}-\mathrm{Au}} / N_{\mathrm{Au}-\mathrm{Ni}}=1.78$, are much greater than $x_{\mathrm{Au}} / x_{\mathrm{Ni}}(=1)$, indicating that more Ni-Ni and $\mathrm{Au}-\mathrm{Au}$ bonds are present than in the AuNi-a/C sample. The numbers and their orders of $N_{\mathrm{Ni}-\mathrm{Ni}}$ $(8.1)>N_{\mathrm{Au}-\mathrm{Au}}(6.7)>N_{\mathrm{Au}-\mathrm{Ni}}\left(=N_{\mathrm{Ni}-\mathrm{Au}}=3.8\right)$ and $J_{\mathrm{Au}}(72 \%)>J_{\mathrm{Ni}}(63 \%)$ demonstrate that the AuNi-cs/C substrate has a core-shell structure with Ni-rich core and Au-rich shell. ${ }^{37}$ In addition, the sum of coordination numbers for $\mathrm{Ni}\left(N_{\mathrm{Ni}-\mathrm{Ni}}+N_{\mathrm{Ni}-\mathrm{Au}}=11.9\right)$ is close to 12 , suggesting that no $\mathrm{Ni}$ atom is involved in the surface layer. The $N_{\mathrm{Au}-\mathrm{Au}}$ value implies that the shells comprise 1 2 Au layers. ${ }^{36,48}$ The $R_{\mathrm{Au}-\mathrm{Au}}$ of AuNi-a/C (2.795 $\AA$ ) is shorter than that of AuNi-cs/C (2.802 A), while the both are much shorter than that of bulk Au (2.866 $\AA$ ). The EXAFS fitting results are thus well consistent with the STEM-EELS observations and XRD measurements shown in Figure 2 and Figure 3, respectively.

Table 1. Coordination numbers and alloying extent for AuNi nanoparticles

\begin{tabular}{ccccccccc}
\hline & $N_{\mathrm{Au}-\mathrm{Au}}$ & $N_{\mathrm{Au}-\mathrm{Ni}}$ & $N_{\mathrm{Ni}-\mathrm{Ni}}$ & $N_{\mathrm{Ni}-\mathrm{Au}}$ & $P_{\text {observed }}$ & $R_{\text {observed }}$ & $J_{A u}(\%)$ & $J_{N i}(\%)$ \\
$\mathrm{AuNi}-\mathrm{HS} / \mathrm{C}$ & 6.7 & 3.8 & 8.1 & 3.8 & 0.36 & 0.32 & 72 & 63 \\
$\mathrm{AuNi}-\mathrm{a} / \mathrm{C}$ & 5.4 & 4.7 & 5.7 & 4.7 & 0.47 & 0.45 & 93 & 91 \\
\hline
\end{tabular}

We adopted $\mathrm{Au} / \mathrm{C}, \mathrm{AuNi}-\mathrm{cs} / \mathrm{C}$, and $\mathrm{AuNi}-\mathrm{a} / \mathrm{C}$ as a metal core to support $\mathrm{Pt}_{\mathrm{ML}}$ catalysts that were prepared via galvanic replacement of UPD Cu monolayer (Cu UPD curves are shown in Figure S5) with Pt. To investigate the influence of different cores on the Pt ML, we applied the cyclic voltammetric (CV) technique in an Ar-saturated $0.1 \mathrm{M} \mathrm{HClO}_{4}$ solution shown in 
Figure 5a compared to that of the Pt/C. The ECSAs determined by integrating the peaks of under-potential deposition of hydrogen $\left(\mathrm{H}_{\mathrm{UPD}}\right)$ over time in the CVs are $115 \mathrm{~m}^{2} \mathrm{~g}^{-1}, 119 \mathrm{~m}^{2}$ $\mathrm{g}^{-1}$, and $124 \mathrm{~m}^{2} \mathrm{~g}^{-1}$ for $\mathrm{Pt}_{\mathrm{ML}} \mathrm{Au} / \mathrm{C}, \mathrm{Pt}_{\mathrm{ML}} \mathrm{AuNi}-\mathrm{Cs} / \mathrm{C}$, and $\mathrm{Pt}_{\mathrm{ML}} \mathrm{AuNi}-\mathrm{a} / \mathrm{C}$, respectively. Furthermore, comparison of their surface oxidation above $0.70 \mathrm{~V}$ to that of the $\mathrm{Pt} / \mathrm{C}$, we found that all three cores resulted in an obvious positive shift of the reduction potential of electro-adsorbed oxygenated species on $\mathrm{Pt}_{\mathrm{ML}}$ surfaces. This indicates that the oxygen affinity of these Pt MLs is weakened, which is the equivalent of the down shifts of the d-band centers of the Pt MLs relative to Pt/C based on the density functional theory (DFT) calculations of Nørskov's group. ${ }^{49-52}$ As for the $\mathrm{Pt}_{\mathrm{ML}} \mathrm{Au} / \mathrm{C}$, it was suggested that the destabilization of electro-adsorbed oxygenated species was largely due to the modified electronic structure of the $\mathrm{Pt}_{\mathrm{ML}}$ that can be attributed to the increased compressive surface strain on the Au core nanoparticles compared to the bulk. ${ }^{53,54}$ Besides, among these three $\mathrm{Pt}_{\mathrm{ML}}$ catalysts, the $\mathrm{Pt}_{\mathrm{ML}} \mathrm{AuNi}-\mathrm{a} / \mathrm{C}$ owns the largest shift $\left(\sim 24 \mathrm{mV}\right.$ shift for $\mathrm{Pt}_{\mathrm{ML}} \mathrm{Au} / \mathrm{C}, \sim 39 \mathrm{mV}$ shift for $\mathrm{Pt}_{\mathrm{ML}} \mathrm{AuNi}-\mathrm{cs} / \mathrm{C}$, and $\sim 52 \mathrm{mV}$ shift for $\mathrm{Pt}_{\mathrm{ML}} \mathrm{AuNi}-\mathrm{a} / \mathrm{C}$, respectively, highlighted by the dash lines in Figure 5a), so confirming the further strain-induced structure of the intimate alloy core- $\mathrm{Pt}_{\mathrm{ML}}$ shell. 

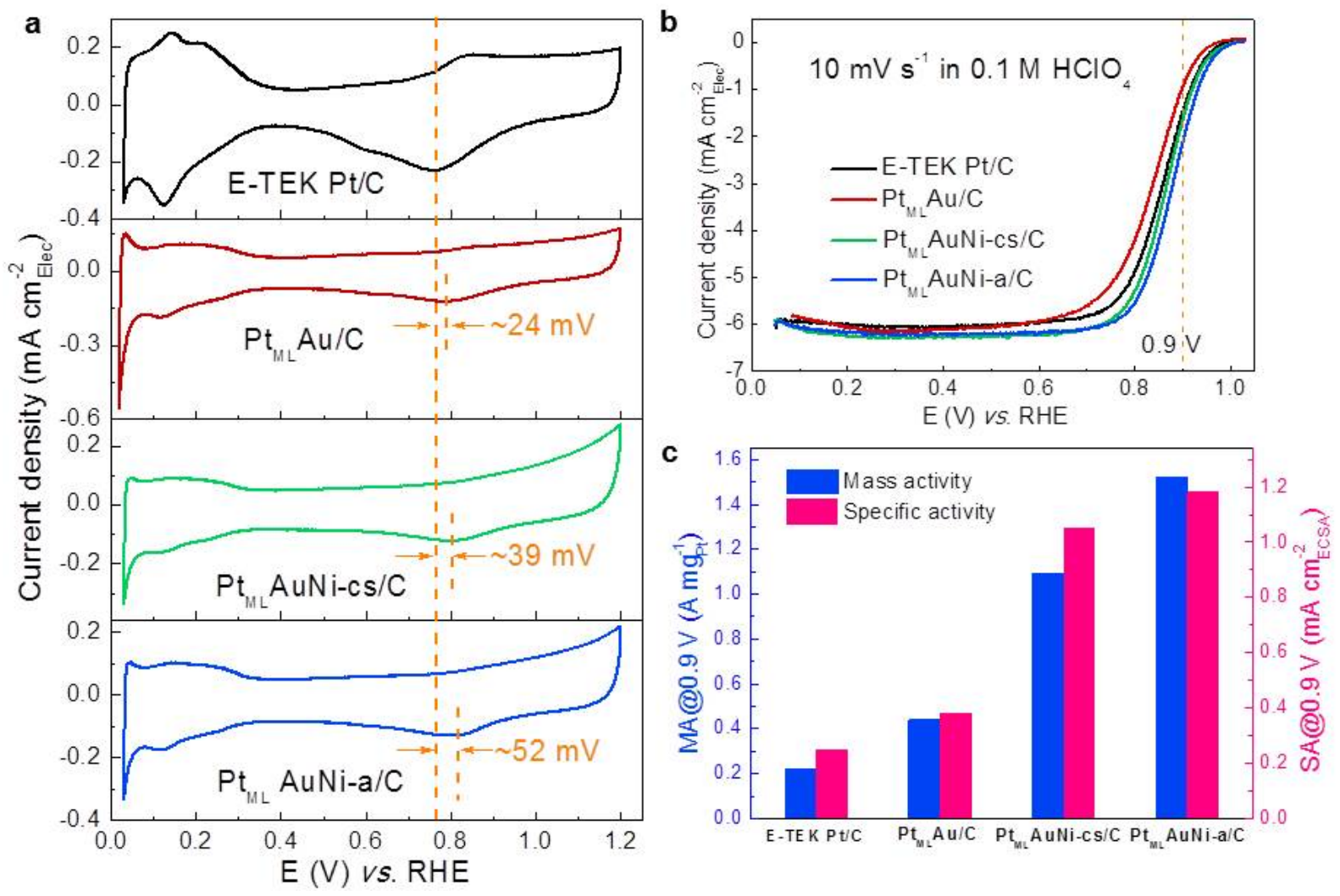

Figure 5. (a) Cyclic voltammetry curves $\left(20 \mathrm{mV} \mathrm{s}^{-1}\right)$ and (b) ORR polarization curves (10 $\mathrm{mV} \mathrm{s}^{-1}, 1600 \mathrm{rpm}$ ) of E-TEK Pt/C, $\mathrm{Pt}_{\mathrm{ML}} \mathrm{Au} / \mathrm{C}, \mathrm{Pt}_{\mathrm{ML}} \mathrm{AuNi}-\mathrm{cs} / \mathrm{C}$, and $\mathrm{Pt}_{\mathrm{ML}} \mathrm{AuNi}-\mathrm{a} / \mathrm{C}$ with the Pt loadings of $10.2 \mu \mathrm{g} \mathrm{cm}^{-2}, 2.70 \mu \mathrm{g} \mathrm{cm}^{-2}, 2.14 \mu \mathrm{g} \mathrm{cm}^{-2}$, and $2.23 \mu \mathrm{g} \mathrm{cm}^{-2}$, respectively, obtained in $0.1 \mathrm{M} \mathrm{HClO}_{4}$ solutions. (c) Pt mass and specific activities of electrocatalysts at $0.9 \mathrm{~V}$.

We evaluated the ORR kinetics of the $\mathrm{Pt}_{\mathrm{ML}}$ electrocatalysts on these core-shell- and alloyed-metallic cores by comparing their polarization curves that were acquired in $\mathrm{O}_{2}$-saturated $0.1 \mathrm{M} \mathrm{HClO}_{4}$ (Figure 5b) and then calculated their activities based on Koutecký-Levich plots (Figure S6). Among all these electrocatalysts, $\mathrm{Pt}_{\mathrm{ML}} \mathrm{AuNi}-\mathrm{a} / \mathrm{C}$ produced the highest Pt mass- and specific-activity of $1.52 \mathrm{~A} \mathrm{mg}^{-1}$ Pt and $1.18 \mathrm{~mA} \mathrm{~cm}^{-2}$ ECSA, respectively, nearly 7- and 5-times higher than that of the $\mathrm{Pt} / \mathrm{C}$. In addition, the ORR activities are normalized by the total mass of Pt and Au (Figure S7), the mass activity of $\mathrm{Pt}_{\mathrm{ML}} \mathrm{AuNi}-\mathrm{a} / \mathrm{C}$ is $0.34 \mathrm{~A} \mathrm{mg}^{-1}{ }_{(\mathrm{Pt}+\mathrm{Au})}$, which is 1.5 and 3 times higher than that of the standard $\mathrm{Pt} / \mathrm{C}$ and $\mathrm{Pt}_{\mathrm{ML}} \mathrm{Au} / \mathrm{C}$, respectively. As shown in Figure $5 \mathrm{c}$, both the Pt mass and specific 
activities increase in the order of $\mathrm{Pt} / \mathrm{C}<\mathrm{Pt}_{\mathrm{ML}} \mathrm{Au} / \mathrm{C}<\mathrm{Pt}_{\mathrm{ML}} \mathrm{AuNi}-\mathrm{cs} / \mathrm{C}<\mathrm{Pt}_{\mathrm{ML}} \mathrm{AuNi}-\mathrm{a} / \mathrm{C}$. The higher activity of $\mathrm{Pt}_{\mathrm{ML}} \mathrm{Au} / \mathrm{C}$ catalysts compared to the commercial $\mathrm{Pt} / \mathrm{C}$ has been reported previously, ${ }^{53,54}$ and it was rationalized that the activity enhancement would be caused by the increased compressive surface strain on the Au core nanoparticles compared to the Au bulk. ${ }^{53}$ The present study showed that the Ni atoms incorporated in Au nanoparticle cores further increases the ORR activity of Pt MLs. As shown in the XRD and XAS measurements, the bond distances of $\mathrm{Au}-\mathrm{Au}$ atoms in $\mathrm{AuNi}-\mathrm{cs} / \mathrm{C}$ and $\mathrm{AuNi}-\mathrm{a} / \mathrm{C}$ are contracted significantly compared with that in Au. Pt-Pt bond distances in Pt MLs deposited on these AuNi cores should also be contracted and thus the $d$-band centers of Pt MLs could be shifted downwards compared with that of $\mathrm{Pt}_{\mathrm{ML}} / \mathrm{Au} / \mathrm{C}$, thereby leading to optimum Pt-O binding strength. We envisage that such the geometrical effect is a prime factor for the enhancement in ORR for the $\mathrm{Pt}_{\mathrm{ML}} \mathrm{AuNi} / \mathrm{C}$ catalysts. We consider that the electronic effect is also operative. The XANES spectra demonstrated that $d$-band fillings of $\mathrm{Au}$ in AuNi-cs/C and AuNi-a/C are lowered in the presence of $\mathrm{Ni}$ atoms (Figure 4a), and such the electronic effect may be coupled with the geometric effect, resulting in the marked improvement of ORR activity in Pt ML on AuNi core (although it is difficult to partition the geometrical and electronic effects quantitatively). The effects are much pronounced for the alloy-structured $\mathrm{Pt}_{\mathrm{ML}} \mathrm{AuNi}-\mathrm{a} / \mathrm{C}$ catalyst compared with the core-shell $\mathrm{Pt}_{\mathrm{ML}} \mathrm{AuNi}$-cs/C catalyst; for instance, the XRD analysis (Table S1) showed the lattice constant $a$ decreases in the order of Au (4.086 $\AA$ ) $>$ AuNi-cs/C (3.996 $\AA)>$ AuNi-a/C (3.861 $\AA$ ). We should note that the lattice constants of Pt bulk and nanoparticles are $3.923 \AA$ and ca. $3.915 \AA$ (for Pt nanoparticle with a $5 \mathrm{~nm}$ diameter). ${ }^{55}$ The $\mathrm{Pt}_{\mathrm{ML}} \mathrm{AuNi}-\mathrm{a} / \mathrm{C}$ catalyst suffers from the most severe contraction in Pt-Pt bond among the 
catalysts examined in this study (Figure S8), which is even lowered than that of Pt nanoparticles, and as a consequence it shows the highest activity. It is worth pointing out that our $\mathrm{Pt}_{\mathrm{ML}} \mathrm{Au} / \mathrm{C}$ shows mass- and specific-activity of $0.44 \mathrm{~A} \mathrm{mg}^{-1} \mathrm{Pt}$ and $0.38 \mathrm{~mA} \mathrm{~cm}{ }_{\mathrm{ECSA}}$, which is lower than that of the $\mathrm{Pt}_{\mathrm{ML}} \mathrm{Au} / \mathrm{C}$ reported recently by Shao and Higuchi, ${ }^{53,54}$ respectively. The lower activity we observed is due to the larger size of our Au core (5 nm). Their studies have demonstrated that the ORR activity of $\mathrm{Pt}_{\mathrm{ML}} \mathrm{Au} / \mathrm{C}$ is highly dependent on the particle size of Au core, viz. the smaller particle size, the higher ORR activity, as suggested by them. However, our $\mathrm{Pt}_{\mathrm{ML}} \mathrm{AuNi}-\mathrm{a} / \mathrm{C}$ exhibits the ORR activity, especially the specific activity, higher than their $\mathrm{Pt}_{\mathrm{ML}} \mathrm{Au} / \mathrm{C}$ catalysts, although the particle size of the AuNi-a $(5.8 \mathrm{~nm})$ is larger than that of the Au $(2-3 \mathrm{~nm})$ they used. In addition, the ORR activity of the $\mathrm{Pt}_{\mathrm{ML}} \mathrm{AuNi}-\mathrm{a} / \mathrm{C}$ is also higher that of the $\mathrm{Pt}_{\mathrm{ML}}$ supported on the $\mathrm{Ni}_{0.5} \mathrm{Fe} @ \mathrm{Au}$ core-shell nanoparticles reported in our previous work. ${ }^{28}$

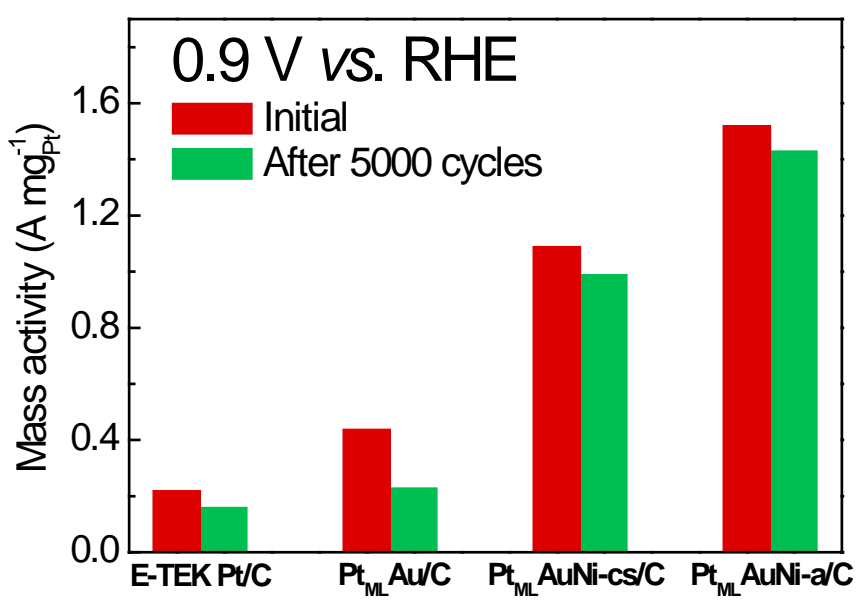

Figure 6. Comparison of $\mathrm{Pt}$ mass activities of $\mathrm{Pt} / \mathrm{C}, \mathrm{Pt}_{\mathrm{ML}} \mathrm{Au} / \mathrm{C}, \mathrm{Pt}_{\mathrm{ML}} \mathrm{AuNi}-\mathrm{Cs} / \mathrm{C}$, and $\mathrm{Pt}_{\mathrm{ML}} \mathrm{AuNi}-\mathrm{a} / \mathrm{C}$ before (red) and after (green) stability test.

We further used the Pt/C as reference to interrogate the stability of these electrocatalysts by applying potential cycles between 0.6 and $1.0 \mathrm{~V}$ (Figure S9). Figure S10 shows the 
polarization curves of the $\mathrm{Pt} / \mathrm{C}, \mathrm{Pt}_{\mathrm{ML}} \mathrm{Au} / \mathrm{C}, \mathrm{Pt}_{\mathrm{ML}} \mathrm{AuNi}-\mathrm{Cs} / \mathrm{C}$, and $\mathrm{Pt}_{\mathrm{ML}} \mathrm{AuNi}-\mathrm{a} / \mathrm{C}$ before and after 5,000 potential cycle test. The $\mathrm{Pt}_{\mathrm{ML}} \mathrm{Au} / \mathrm{C}$ lost its ORR activity much faster than the $\mathrm{Pt} / \mathrm{C}$, i.e., $48 \%$ loss of mass activity for $\mathrm{Pt}_{\mathrm{ML}} \mathrm{Au} / \mathrm{C}$ catalyst versus $27 \%$ loss of mass activity for $\mathrm{Pt} / \mathrm{C}$. In contrast, the ORR activity of the $\mathrm{Pt}_{\mathrm{ML}} \mathrm{AuNi}-\mathrm{cs} / \mathrm{C}$ and $\mathrm{Pt}_{\mathrm{ML}} \mathrm{AuNi}-\mathrm{a} / \mathrm{C}$ electrocatalysts remained almost the same as their respective RDE voltammograms nearly overlapped before and after the stability test. The kinetic currents at $0.9 \mathrm{~V}$ for all the studied electrocatalysts obtained from the Koutecký-Levich equation were used to get Pt mass activities (Figure 6 and Table S3). It can be seen that, even after 5,000-cycles the mass activities of $\mathrm{Pt}_{\mathrm{ML}} \mathrm{AuNi}-\mathrm{cs} / \mathrm{C}$ and $\mathrm{Pt}_{\mathrm{ML}} \mathrm{AuNi}-\mathrm{a} / \mathrm{C}$ were more than 4.5 and 6.5 times greater than that of the initial Pt/C. Our previous work discussed that Au was able to stabilize Pt nanoparticles because Au can elevate the oxidation potential of $\mathrm{Pt}^{5}$ The same origin of the stability might be true for our $\mathrm{Pt}_{\mathrm{ML}} \mathrm{AuNi}-\mathrm{cs} / \mathrm{C}$ and $\mathrm{Pt}_{\mathrm{ML}} \mathrm{AuNi}-\mathrm{a} / \mathrm{C}$ catalysts. However, this seemingly contradicted with the significant loss of the ORR activity for $\mathrm{Pt}_{\mathrm{ML}} \mathrm{Au} / \mathrm{C}$ upon potential cycles under the same condition. These counterintuitive observations could most likely highlight the essential role of $\mathrm{Ni}$ in $\mathrm{Pt}_{\mathrm{ML}} \mathrm{AuNi}-\mathrm{Cs} / \mathrm{C}$ and $\mathrm{Pt}_{\mathrm{ML}} \mathrm{AuNi}-\mathrm{a} / \mathrm{C}$ catalysts that modify the electronic properties and crystalline lattice of $\mathrm{Au}$ and then its interaction with the $\mathrm{Pt}_{\mathrm{ML}}$. Besides DFT calculations have shown that near surface Au atoms from the AuNi alloy tend to segregate to the Pt shell especially to the vertex and edge sites of the nanoparticle promoting the durability of the catalyst. ${ }^{26}$

\section{CONCLUSIONS}

We investigated the effect of $\mathrm{Au}$ component, composition, and steric configuration on $\mathrm{Pt}$ 
monolayer electrocatalysts employing a comparative approach. The $\mathrm{Pt}_{\mathrm{ML}}$ on AuNi alloyed core performed much better for ORR not only than the Pt/C but also than the $\mathrm{Pt}_{\mathrm{ML}}$ on $\mathrm{AuNi}$ core-shelled core. As Au substrate alone deteriorate the performance of $\mathrm{Pt}_{\mathrm{ML}}$, alloying of $\mathrm{Au}$ with Ni fine-tuned the electronic properties of $\mathrm{Au}$ and induced geometric effect expediting the ORR activity. Geometric-, ligand- and segregation-effects are accounted for the enhanced stability of $\mathrm{Pt}_{\mathrm{ML}} \mathrm{AuNi} / \mathrm{C}$ electrocatalysts. The structure-determined electrochemical properties, together with AuNi alloy as a support, offered a new avenue to the basic and applied research on Pt-based ORR electrocatalysts for electrochemical energy devices such as fuel cells and metal-air batteries.

\section{ASSOCIATED CONTENT}

\section{Supporting Information Available}

Thermodynamic phase diagram, TEM and SEM-EDX analysis, additional XRD and EXAFS data, additional electrochemical data, and models of Pt monolayer. This material is available free of charge via the Internet at http://pubs.acs.org.

\section{AUTHOR INFORMATION}

Corresponding Authors

*adzic@bnl.gov

*yingphit@hit.edu.cn

*ksasaki@bnl.gov 


\section{Notes}

The authors declare no competing financial interests.

\section{ACKNOWLEDGEMENTS}

This manuscript has been authored by employees/guests of Brookhaven Science Associates, LLC under Contract No. DE-SC0012704 with the U.S. Department of Energy. The publisher by accepting the manuscript for publication acknowledges that the United States Government retains a non-exclusive, paid-up, irrevocable, world-wide license to publish or reproduce the published form of this manuscript, or allow others to do so, for United States Government purposes. This work was also conducted under the framework of National Natural Science Foundation of China (Project No. 21276058 and 21433003) and State Key Laboratory of Urban Water Resource and Environment, Harbin Institute of Technology (Project No. 2014DX10). Beam lines X18A and X19A at the NSLS are supported in part by the Synchrotron Catalysis Consortium, US DOE Grant No. DE-FG02-05ER15688. G. Y. Chen thanks J. X. Wang, W. P. Zhou, Y. Zhang, S. Bliznakov, K. He, Y. P. Zhang, and Y. Y. Li for their kind assistance, and acknowledges the financial support from both the China Scholarship Council and Brookhaven National Laboratory (BNL) to perform his work at BNL. 


\section{REFERENCES}

(1) Strasser, P., Catalysts by Platonic design. Science 2015, 349, 379-380.

(2) Zhang, L.; Roling, L. T.; Wang, X.; Vara, M.; Chi, M. F.; Liu, J. Y.; Choi, S. I.; Park, J.; Herron, J. A.; Xie, Z. X.; Mavrikakis, M.; Xia, Y. N., Platinum-based nanocages with subnanometer-thick walls and well-defined, controllable facets. Science 2015, 349, 412-416.

(3) Chen, C.; Kang, Y. J.; Huo, Z. Y.; Zhu, Z. W.; Huang, W. Y.; Xin, H. L. L.; Snyder, J. D.; Li, D. G.; Herron, J. A.; Mavrikakis, M.; Chi, M. F.; More, K. L.; Li, Y. D.; Markovic, N. M.; Somorjai, G. A.; Yang, P. D.; Stamenkovic, V. R., Highly Crystalline Multimetallic Nanoframes with Three-Dimensional Electrocatalytic Surfaces. Science 2014, 343, $1339-1343$.

(4) Sasaki, K.; Naohara, H.; Choi, Y. M.; Cai, Y.; Chen, W. F.; Liu, P.; Adzic, R. R., Highly stable Pt monolayer on PdAu nanoparticle electrocatalysts for the oxygen reduction reaction. Nat. Commun. 2012, 3, 1115.

(5) Zhang, J.; Sasaki, K.; Sutter, E.; Adzic, R. R., Stabilization of platinum oxygen-reduction electrocatalysts using gold clusters. Science 2007, 315, 220-222.

(6) Amanullah, S.; Das, P. K.; Samanta, S.; Dey, A., Tuning the thermodynamic onset potential of electrocatalytic $\mathrm{O}_{2}$ reduction reaction by synthetic iron-porphyrin complexes. Chem. Commun. 2015, 51, 10010-10013.

(7) Koper, M. T. M., Thermodynamic theory of multi-electron transfer reactions: Implications for electrocatalysis. J. Electroanal. Chem. 2011, 660, 254-260.

(8) Ramaswamy, N.; Tylus, U.; Jia, Q. Y.; Mukerjee, S., Activity Descriptor Identification for Oxygen Reduction on Nonprecious Electrocatalysts: Linking Surface Science to 
Coordination Chemistry. J. Am. Chem. Soc. 2013, 135, 15443-15449.

(9) Yang, L. J.; Jiang, S. J.; Zhao, Y.; Zhu, L.; Chen, S.; Wang, X. Z.; Wu, Q.; Ma, J.; Ma, Y. W.; Hu, Z., Boron-Doped Carbon Nanotubes as Metal-Free Electrocatalysts for the Oxygen Reduction Reaction. Angew. Chem. Int. Ed. 2011, 50, 7132-7135.

(10) Black, R.; Lee, J. H.; Adams, B.; Mims, C. A.; Nazar, L. F., The Role of Catalysts and Peroxide Oxidation in Lithium-Oxygen Batteries. Angew. Chem. Int. Ed. 2013, 52, 392-396.

(11) Kuttiyiel, K. A.; Sasaki, K.; Su, D.; Wu, L. J.; Zhu, Y. M.; Adzic, R. R., Gold-promoted structurally ordered intermetallic palladium cobalt nanoparticles for the oxygen reduction reaction. Nat. Commun. 2014, 5, 5185.

(12) Wu, G.; More, K. L.; Johnston, C. M.; Zelenay, P., High-Performance Electrocatalysts for Oxygen Reduction Derived from Polyaniline, Iron, and Cobalt. Science 2011, 332, 443-447.

(13) Lefevre, M.; Proietti, E.; Jaouen, F.; Dodelet, J. P., Iron-Based Catalysts with Improved Oxygen Reduction Activity in Polymer Electrolyte Fuel Cells. Science 2009, 324, 71-74.

(14)Li, Q. Q.; Noffke, B. W.; Wang, Y. L.; Menezes, B.; Peters, D. G.; Raghavachari, K.; Li, L. S., Electrocatalytic Oxygen Activation by Carbanion Intermediates of Nitrogen-Doped Graphitic Carbon. J. Am. Chem. Soc. 2014, 136, 3358-3361.

(15) Gong, K. P.; Du, F.; Xia, Z. H.; Durstock, M.; Dai, L. M., Nitrogen-Doped Carbon Nanotube Arrays with High Electrocatalytic Activity for Oxygen Reduction. Science 2009, 323, $760-764$.

(16) Debe, M. K., Electrocatalyst approaches and challenges for automotive fuel cells. Nature 2012, 486, 43-51. 
(17) Gasteiger, H. A.; Kocha, S. S.; Sompalli, B.; Wagner, F. T., Activity benchmarks and requirements for Pt, Pt-alloy, and non-Pt oxygen reduction catalysts for PEMFCs. Appl. Catal. B 2005, 56, 9-35.

(18) Stamenkovic, V. R.; Mun, B. S.; Arenz, M.; Mayrhofer, K. J. J.; Lucas, C. A.; Wang, G. F.; Ross, P. N.; Markovic, N. M., Trends in electrocatalysis on extended and nanoscale Pt-bimetallic alloy surfaces. Nat. Mater. 2007, 6, 241-247.

(19) Strasser, P.; Koh, S.; Anniyev, T.; Greeley, J.; More, K.; Yu, C. F.; Liu, Z. C.; Kaya, S.; Nordlund, D.; Ogasawara, H.; Toney, M. F.; Nilsson, A., Lattice-strain control of the activity in dealloyed core-shell fuel cell catalysts. Nat. Chem. 2010, 2, 454-460.

(20) Yang, H., Platinum-Based Electrocatalysts with Core-Shell Nanostructures. Angew. Chem. Int. Ed. 2011, 50, 2674-2676.

(21) Kuttiyiel, K. A.; Choi, Y.; Hwang, S. M.; Park, G. G.; Yang, T. H.; Su, D.; Sasaki, K.; Liu, P.; Adzic, R. R., Enhancement of the oxygen reduction on nitride stabilized Pt-M (M=Fe, Co, and Ni) core-shell nanoparticle electrocatalysts. Nano Energy 2015, 13, 442-449.

(22) Adzic, R., Platinum Monolayer Electrocatalysts: Tunable Activity, Stability, and Self-Healing Properties. Electrocatalysis 2012, 3, 163-169.

(23) Zhang, J. L.; Vukmirovic, M. B.; Sasaki, K.; Nilekar, A. U.; Mavrikakis, M.; Adzic, R. R., Mixed-metal Pt monolayer electrocatalysts for enhanced oxygen reduction kinetics. J. Am. Chem. Soc. 2005, 127, 12480-12481.

(24) Choi, Y. M.; Kuttiyiel, K. A.; Labis, J. P.; Sasaki, K.; Park, G. G.; Yang, T. H.; Adzic, R. R., Enhanced Oxygen Reduction Activity of $\mathrm{IrCu}$ Core Platinum Monolayer Shell Nano-electrocatalysts. Top. Catal. 2013, 56, 1059-1064. 
(25) Sasaki, K.; Naohara, H.; Cai, Y.; Choi, Y. M.; Liu, P.; Vukmirovic, M. B.; Wang, J. X.; Adzic, R. R., Core-Protected Platinum Monolayer Shell High-Stability Electrocatalysts for Fuel-Cell Cathodes. Angew. Chem. Int. Ed. 2010, 49, 8602-8607.

(26) An, W.; Liu, P., Rationalization of Au Concentration and Distribution in AuNi@Pt Core-Shell Nanoparticles for Oxygen Reduction Reaction. ACS Catal. 2015, 5, 6328-6336.

(27) Kuttiyiel, K. A.; Sasaki, K.; Su, D.; Vukmirovic, M. B.; Marinkovic, N. S.; Adzic, R. R., Pt monolayer on Au-stabilized PdNi core-shell nanoparticles for oxygen reduction reaction. Electrochim. Acta 2013, 110, 267-272.

(28) Gong, K. P.; Su, D.; Adzic, R. R., Platinum-Monolayer Shell on AuNi ${ }_{0.5} F e$ Nanoparticle Core Electrocatalyst with High Activity and Stability for the Oxygen Reduction Reaction. $J$. Am. Chem. Soc. 2010, 132, 14364-14366.

(29) Zhang, J.; Lima, F. H.; Shao, M. H.; Sasaki, K.; Wang, J. X.; Hanson, J.; Adzic, R. R., Platinum monolayer on nonnoble metal-noble metal core-shell nanoparticle electrocatalysts for $\mathrm{O}_{2}$ reduction. J. Phys. Chem. B 2005, 109, 22701-22704.

(30) Zhou, S. H.; Jackson, G. S.; Eichhorn, B., AuPt alloy nanoparticles for CO-tolerant hydrogen activation: Architectural effects in Au-Pt bimetallic nanocatalysts. Adv. Funct. Mater. 2007, 17, 3099-3104.

(31) Zhou, S. H.; Yin, H. F.; Schwartz, V.; Wu, Z. L.; Mullins, D.; Eichhorn, B.; Overbury, S. H.; Dai, S., In Situ Phase Separation of NiAu Alloy Nanoparticles for Preparing Highly Active Au/NiO CO Oxidation Catalysts. Chemphyschem 2008, 9, 2475-2479.

(32) Wu, J. B.; Zhang, J. L.; Peng, Z. M.; Yang, S. C.; Wagner, F. T.; Yang, H., Truncated Octahedral $\mathrm{Pt}_{3} \mathrm{Ni}$ Oxygen Reduction Reaction Electrocatalysts. J. Am. Chem. Soc. 2010, 132, 
4984-4985.

(33) Brankovic, S. R.; Wang, J. X.; Adzic, R. R., Metal monolayer deposition by replacement of metal adlayers on electrode surfaces. Surf. Sci. 2001, 474, L173-L179.

(34) Ravel, B.; Newville, M., ATHENA, ARTEMIS, HEPHAESTUS: data analysis for X-ray absorption spectroscopy using IFEFFIT. J. Synchrotron Radiat. 2005, 12, 537-541.

(35) Nashner, M. S.; Frenkel, A. I.; Adler, D. L.; Shapley, J. R.; Nuzzo, R. G., Structural characterization of carbon-supported platinum-ruthenium nanoparticles from the molecular cluster precursor PtRu 5 C(CO) ${ }_{16}$. J. Am. Chem. Soc. 1997, 119, 7760-7771.

(36) Sasaki, K.; Kuttiyiel, K. A.; Barrio, L.; Su, D.; Frenkel, A. I.; Marinkovic, N.; Mahajan, D.; Adzic, R. R., Carbon-Supported IrNi Core-Shell Nanoparticles: Synthesis, Characterization, and Catalytic Activity. J. Phys. Chem. C 2011, 115, 9894-9902.

(37) Hwang, B. J.; Sarma, L. S.; Chen, J. M.; Chen, C. H.; Shih, S. C.; Wang, G. R.; Liu, D. G.; Lee, J. F.; Tang, M. T., Structural models and atomic distribution of bimetallic nanoparticles as investigated by X-ray absorption spectroscopy. J. Am. Chem. Soc. 2005, 127, 11140-11145.

(38) Milazzo, G.; Caroli, S.; Sharma, V. K., Tables of Standard Electrode Potentials. Wiley: Chichester, 1978.

(39) Wang, X. D.; Yu, H. B.; Hua, D. Y.; Zhou, S. H., Enhanced Catalytic Hydrogenation Activity and Selectivity of Pt- $\mathrm{M}_{x} \mathrm{O}_{y} / \mathrm{Al}_{2} \mathrm{O}_{3}(\mathrm{M}=\mathrm{Ni}, \mathrm{Fe}, \mathrm{Co})$ Heteroaggregate Catalysts by in Situ Transformation of PtM Alloy Nanoparticles. J. Phys. Chem. C 2013, 117, 7294-7302.

(40) Ruban, A. V.; Skriver, H. L.; Norskov, J. K., Surface segregation energies in transition-metal alloys. Phys. Rev. B 1999, 59, 15990-16000. 
(41) Hsieh, Y. C.; Zhang, Y.; Su, D.; Volkov, V.; Si, R.; Wu, L. J.; Zhu, Y. M.; An, W.; Liu, P.; He, P.; Ye, S. Y.; Adzic, R. R.; Wang, J. X., Ordered bilayer ruthenium-platinum core-shell nanoparticles as carbon monoxide-tolerant fuel cell catalysts. Nat. Commun. 2013, 4, 2466.

(42) Bzowski, A.; Sham, T. K.; Yiu, Y. M., Ag L-Edge X-Ray-Absorption near-Edge-Structure Study of Charge Redistribution at the Ag Site in Au-Ag Alloys. Phys. Rev. B 1994, 49, 13776-13779.

(43) Kuhn, M.; Sham, T. K., Charge Redistribution and Electronic Behavior in a Series of Au-Cu Alloys. Phys. Rev. B 1994, 49, 1647-1661.

(44) Chin, Y. H.; King, D. L.; Roh, H. S.; Wang, Y.; Heald, S. M., Structure and reactivity investigations on supported bimetallic Au-Ni catalysts used for hydrocarbon steam reforming. J. Catal. 2006, 244, 153-162.

(45) Alayoglu, S.; Zavalij, P.; Eichhorn, B.; Wang, Q.; Frenkel, A. I.; Chupas, P., Structural and Architectural Evaluation of Bimetallic Nanoparticles: A Case Study of Pt-Ru Core-Shell and Alloy Nanoparticles. ACS Nano 2009, 3, 3127-3137.

(46) Frenkel, A. I., Applications of extended X-ray absorption fine-structure spectroscopy to studies of bimetallic nanoparticle catalysts. Chem. Soc. Rev. 2012, 41, 8163-8178.

(47) Frenkel, A., Solving the 3D structure of metal nanoparticles. Zeitschrift Fur Kristallographie 2007, 222, 605-611.

(48) Sasaki, K.; Wang, J. X.; Naohara, H.; Marinkovic, N.; More, K.; Inada, H.; Adzic, R. R., Recent advances in platinum monolayer electrocatalysts for oxygen reduction reaction: Scale-up synthesis, structure and activity of Pt shells on Pd cores. Electrochim. Acta 2010, 55, $2645-2652$. 
(49) Ruban, A.; Hammer, B.; Stoltze, P.; Skriver, H. L.; Norskov, J. K., Surface electronic structure and reactivity of transition and noble metals. J. Mol. Catal. A: Chem. 1997, 115, 421-429.

(50) Kitchin, J. R.; Norskov, J. K.; Barteau, M. A.; Chen, J. G., Role of strain and ligand effects in the modification of the electronic and chemical properties of bimetallic surfaces. Phys. Rev. Lett. 2004, 93, 156801.

(51) Greeley, J.; Norskov, J. K., A general scheme for the estimation of oxygen binding energies on binary transition metal surface alloys. Surf. Sci. 2005, 592, 104-111.

(52) Norskov, J. K.; Abild-Pedersen, F.; Studt, F.; Bligaard, T., Density functional theory in surface chemistry and catalysis. Proc. Natl. Acad. Sci. U. S. A. 2011, 108, 937-943.

(53) Shao, M. H.; Peles, A.; Shoemaker, K.; Gummalla, M.; Njoki, P. N.; Luo, J.; Zhong, C. J., Enhanced Oxygen Reduction Activity of Platinum Monolayer on Gold Nanoparticles. J. Phys. Chem. Lett. 2011, 2, 67-72.

(54) Higuchi, E.; Okada, K.; Chiku, M.; Inoue, H., Electrocatalytic Activity for Oxygen Reduction Reaction of Au Core/Pt Shell Nanoparticle-Loaded Carbon Black Catalyst with Different Core Sizes. Electrochim. Acta 2015, 179, 100-107.

(55) Leontyev, I. N.; Kuriganova, A. B.; Leontyev, N. G.; Hennet, L.; Rakhmatullin, A.; Smirnova, N. V.; Dmitriev, V., Size dependence of the lattice parameters of carbon supported platinum nanoparticles: X-ray diffraction analysis and theoretical considerations. RSC Adv. 2014, 4, 35959-35965. 


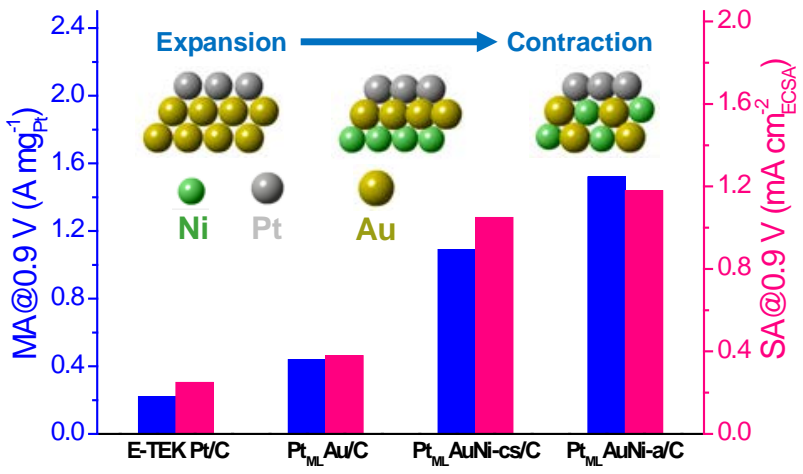

